\title{
DESEMPENHO DE OVINOS SANTA INÊS SUPLEMENTADOS EM TRÊS GRAMÍNEAS PASTEJADAS DURANTE O PERÍODO SECO
}

\author{
PERFORMANCE OF SUPLEMENTED SANTA INÊS SHEEP \\ IN THREE GRASSES GRAZED DURING THE DRY SEASON
}

\author{
Menezes, L.F. de O. ${ }^{1}$, Louvandini, H. ${ }^{1 A}$, Martha Júnior, G.B. ${ }^{2}$, McManus, C. ${ }^{1}$, \\ Barroso, G.G.J.E. ${ }^{1}$ e Mendes, M.C. de B. ${ }^{1}$
}

${ }^{1}$ Faculdade de Agronomia e Medicina Veterinária. Universidade de Brasília. Campus Universitário Darcy Riberio. CEP 70910-900. Brasília-DF. Brasil. Ahlouvand@unb.br

Embrapa-Cecat. Parque Estação Biológica. PqEB s/n. CEP 70770-901. Brasília, DF. Brasil.

\section{PalaVRas ChaVE ADICIONAIS \\ Andropogon. Aruana. Tanzânia. Terminação.}

\section{RESUMO}

Avaliou-se o desempenho de ovinos da raça Santa Inês, em três gramíneas forrageiras tropicais (A. gayanus Kunth. cv. Planaltina, $P$. maximum Jacq. cv. Aruana e P. maximum Jacq. cv. Tanzânia), em pastejo rotacionado, com período de ocupação de 14 dias e lotação fixa de 22 animais/ha, no período da seca. O período experimental foi de 82 dias, onde o desempenho de 11 borregos, em cada tratamento, foi acompanhado em um delineamento inteiramente casualizado. Com o avançar da seca foram utilizados níveis crescentes de 300, 400 e $500 \mathrm{~g} / \mathrm{animal} / \mathrm{dia}$ de suplementação concentrada para os três tratamentos. Nas forragens foram colhidas amostras a cada 14 dias para efetuar as análises bromatológicas. Através da verificação do peso dos animais, realizadas a cada 14 dias, foram obtidos o peso vivo, o ganho médio diário (GMD), o peso final (PF), o ganho acumulado (GAC) e a condição corporal (CC). Os ovinos alimentados com Aruana e Tanzânia apresentaram GMD de 93,6 e 92,0 g/animal/dia, respectivamente não diferindo entre si $(p>0,05)$, mas foram superiores aos do Andropogon 35,6 g/animal/dia $(p<0,05)$. Para PF, GAC e CC os tratamentos Aruana e Tanzânia também proporcionaram os melhores resultados $(p<0,05)$, quando comparados aos observados com o tratamento Andropogon. Os tratamentos Aruana e Tanzânia proporcionaram melhores desempenhos dos ovinos durante o período seco em relação ao Andropogon.

Recibido: 24-7-07. Aceptado: 1-4-08.

\author{
AdDitional KeYWORDS \\ Andropogon. Aruana. Tanzania. Finishing.
}

\section{SUMMARY}

The performance of Santa Inês sheep on three tropical grasses (A. gayanus Kunth. cv. Planaltina, $P$. maximum Jacq. cv. Aruana and $P$. maximum Jacq. cv. Tanzânia), and rotational grazing with an occupation period of 14 days and fixed stocking rate of 22 animals/ha, was evaluated in the dry season. The experimental period was 82 days, and the individual performance of 11 lambs on each treatment was measured. With the progression of the dry season, increasing levels of concentrate supplementation was used $(300$, 400 and $500 \mathrm{~g} /$ animal/day for each of the three treatments). Samples of grass leaf blades were taken each 14 days, and bromatological analysis carried out. The weight of animals, measured each 14 days, was used to calculate average dairy gain (GMD), final weight (PF), accumulated gain (GAC) and body condition (CC). The treatments Aruana and Tanzânia showed highest $(p<0.05)$ GMD, respectively with 93.6 and $92.0 \mathrm{~g} /$ animal/day, not differing between each other $(p>0.05)$. The animals on Andropogon pasture showed a mean weight gain of $35.6 \mathrm{~g} /$ animal/day. For PF, GAC and CC the treatments Aruana and Tanzânia showed the best results $(p<0.05)$, when compared with Andropogon. The forage Aruana and Tanzânia, caused better performance in sheep during the dry season compared to Andropogon.

\section{INTRODUÇÃO}

O cordeiro é a categoria de produção de 
carne ovina que melhor oferece as características de carcaça exigidas pelo mercado consumidor, estando estas relacionadas à alta proporção de músculo e adequada distribuição de gordura, sem excessos. O capim Andropogon (Andropogon gayanus cv. Planaltina) é uma das forrageiras utilizadas na produção de cordeiros em regiões tropicais, devido a fatores ligados a sua baixa exigência de fertilidade e tolerância à acidez. Entretanto, o capim Andropogon não possibilita elevado desempenho animal quando diferido no final das águas para uso no período seco, tendo em vista a acentuada redução na quantidade de lâminas foliares, e no valor nutritivo dessa forrageira. Nos últimos anos, tem sido recomendada a utilização de cultivares do gênero Panicum, mas há pouca informação sobre o desempenho de ovinos nessas pastagens, gerando questionamentos quanto a sua potencialidade para a produção de ovinos a pasto durante o período seco (Curi, 2004).

Objetivou-se com este trabalho avaliar o desempenho produtivo de ovinos, durante o período seco, em pastagens de Andropogon gayanus Kunth. cv. Planaltina e Panicum maximum Jacq. cvs. Aruana e Tanzânia.

\section{MATERIAL E MÉTODOS}

O estudo foi realizado na Fazenda Água Limpa, da Universidade de Brasília (UnB). O período experimental foi de 82 dias, de junho a agosto de 2005, com média de precipitação de $8,8 \mathrm{~mm} / \mathrm{mês}$. O delineamento experimental foi o inteiramente casualizado composto por três tratamentos, gramíneas forrageiras tropicais (A. gayanus cv. Planaltina, $P$. maximum cv. Aruana e $P$. maximum cv. Tanzânia), em áreas de 1 ha para cada, divididas em 4 piquetes de 0,25 ha. O período de ocupação foi de 14 dias e o de descanso de 42 dias, com taxa de lotação fixa de 22 animais/ ha, onde foram utilizados 11 animais testadores por tratamento (cordeiros da raça Santa Inês), com idade inicial média de 90 dias e peso inicial médio de $18,8 \pm 2,88 \mathrm{~kg}$. A taxa de lotação medial inicial foi de $667 \pm 7,05$ $\mathrm{kg} / \mathrm{ha}$ de peso vivo (PV). Os animais receberam suplemento alimentar diária da seguinte mistura de concentrados: $50 \%$ de milho moído, $30 \%$ de farelo de soja e $20 \%$ de farelo de trigo. A quantidade ofertada foi crescente, partindo de $300 \mathrm{~g} / \mathrm{animal} / \mathrm{dia}$ nos primeiros três períodos de 14 dias, $400 \mathrm{~g} /$ animal/dia no quarto e no quinto período e $500 \mathrm{~g} / \mathrm{animal} /$ dia no último período. O fornecimento do sal mineral (Nutron ${ }^{\circledR}$ ) foi ad libitum.

Para a determinação da massa seca foliar foram colhidas dez amostras por tratamento por período, em pré-pastejo e em póspastejo, utilizando quadrado de $0,25 \mathrm{~m}^{2} \mathrm{e}$ cortes ao nível do solo. A cada 14 dias amostras das forrageiras foram colhidas pelo método do pastejo simulado, para acompanhar a qualidade bromatológica. As percentagens dos carboidratos não fibrosos (CNF) foram calculadas segundo a equação $\mathrm{CNF}=100-\mathrm{MM}-\mathrm{PB}-\mathrm{EE}-\mathrm{FDN}$, e as percentagens dos nutrientes digestíveis totais (NDT) foram obtidas pela equação proposta por Harlan et al. (1991): NDT= $109,64-(1,479$ x FDA). Os animais foram pesados e avaliados com relação a condição corporal (CC) de 1 a 5, a cada 14 dias.

O procedimento GLM do pacote estatístico SAS (1999) foi utilizado para a análise dos dados, com nível de significância de $5 \%$.

\section{RESULTADOSEDISCUSSÃO}

Os resultados referentes à disponibilidade, análises bromatológicas, cálculos dos CNF e NDT das forragens e concentrado encontram-se na tabela I. O capim Tanzânia apresentou maior massa de lâminas foliares na entrada e na saída dos animais $(p<0,05)$. O capim Aruana proporcionou as maiores médias de PB e EE quando comparado aos outros capins $(p<0,05)$. Para $M M$, os capins Aruana e Tanzânia não diferiram entre si $(p>0,05)$, mas foram superiores 
Tabela I. Massa foliar e análises bromatológicas das gramíneas Andropogon, Aruana e Tanzânia pastejadas durante o período seco e do concentrado ofertado aos ovinos. (Means and standard deviations of bromatological variables in concentrate and leaf blades of the Andropogon, Aruana and Tanzânia grasses).

\begin{tabular}{|c|c|c|c|c|c|}
\hline \multirow[t]{2}{*}{ Variáveis } & \multirow[t]{2}{*}{ Concentrado } & \multicolumn{3}{|c|}{ Gramíneas } & \multirow[t]{2}{*}{ E.P. } \\
\hline & & Andropogon & Aruana & Tanzânia & \\
\hline Lamina foliar a entrada dos animais (t/ha) & - & $0,41^{\mathrm{b}}$ & $0,85^{b}$ & $3,83^{a}$ & 0,24 \\
\hline Lamina foliar a saída dos animais (t/ha) & - & $0,05^{b}$ & $0,18^{b}$ & $3,19^{a}$ & 0,20 \\
\hline Lamina foliar (entrada-saída) (t/ha) & - & 0,36 & 0,67 & 0,64 & 0,25 \\
\hline Matéria seca $(\%)$ & 88,3 & 47,1 & 43,4 & 40,8 & 3,06 \\
\hline Proteína bruta ${ }^{1}$ & 21,7 & $4,1^{\mathrm{a}}$ & $5,1^{\mathrm{b}}$ & $4,2^{\mathrm{a}}$ & 0,35 \\
\hline Fibra em detergente neutro ${ }^{1}$ & 15,8 & 74,3 & 72,2 & 72,7 & 2,86 \\
\hline Fibra em detergente ácido ${ }^{1}$ & 7,3 & $45,5^{a}$ & $42,5^{b}$ & $42,2^{b}$ & 2,80 \\
\hline Extrato etéreo ${ }^{1}$ & 3,1 & $1,5^{b}$ & $2,1^{\mathrm{a}}$ & $1,9^{\mathrm{ab}}$ & 2,93 \\
\hline Matéria mineral ${ }^{1}$ & 3,2 & $4,7^{b}$ & $6,8^{a}$ & $6,9^{a}$ & 0,35 \\
\hline Carboidratos não fibrosos ${ }^{1}$ & 56,1 & 15,4 & 13,8 & 14,3 & 19,95 \\
\hline Nutrientes digestíveis totais ${ }^{1}$ & 98,8 & 42,3 & 46,8 & 47,3 & 2,30 \\
\hline
\end{tabular}

$\mathrm{EP}=$ Erro padrão. ${ }^{1}$ Percentagens relativas a matéria seca (MS). ${ }^{\text {b }}$ Médias seguidas por letras diferentes, entre as gramíneas na mesma linha, apresentaram diferenças significativas $(p<0,05)$.

$(\mathrm{p}<0,05)$ ao Andropogon. Para a FDA, o Andropogon obteve a maior média $(\mathrm{p}<0,05)$.

Para as variáveis de desempenho animal avaliadas apresentadas na tabela II, não se verificaram diferenças $(\mathrm{p}>0,05)$ entre os capins Aruana e Tanzânia, os quais superaram os valores $(p<0,05)$ obtidos no Andropogon. O melhor desempenho animal no capim Tanzânia, em parte, refletiu a maior massa seca de lâminas foliares em pré e em pós-pastejo, favorecendo maior seletividade dos animais. No caso do capim Aruana, o melhor desempenho parece ter sido devido ao teor de proteína mais elevado (tabela I). Os menores teores de FDA nos capins Aruana e Tanzânia corroboraram com o maior

Tabela II. Taxa de lotação ( $\mathrm{kg} / \mathrm{ha}$ de peso vivo, PV) e desempenho de ovinos Santa Inês em três gramíneas tropicais durante o periodo seco. (Stocking rate and animal performance of Santa Inês sheep on three tropical grasses during the dry season).

\begin{tabular}{|c|c|c|c|c|}
\hline \multirow[t]{2}{*}{ Variáveis } & \multicolumn{3}{|c|}{ Tratamentos } & \multirow[t]{2}{*}{ E.P. } \\
\hline & Andropogon & Aruana & Tanzânia & \\
\hline Taxa de lotação inicial (kg/ha) & 656 & 664 & 680 & - \\
\hline Taxa de lotação final (kg/ha ) & 712 & 806 & 825 & - \\
\hline Peso vivo inicial (kg/animal) & 18,4 & 18,6 & 19,5 & 0,88 \\
\hline Peso vivo final (kg/animal) & $21,2^{b}$ & $26,4^{a}$ & $27,1^{\mathrm{a}}$ & 1,25 \\
\hline Ganho médio (g/animal/dia) & $35,6^{b}$ & $93,6^{a}$ & $92,0^{\mathrm{a}}$ & 10,16 \\
\hline Ganho acumulado (kg/82 dias) & $2,8^{b}$ & $7,6^{\mathrm{a}}$ & $7,5^{\mathrm{a}}$ & 0,85 \\
\hline Condição corporal ${ }^{1}$ & $1,6^{b}$ & $1,9^{a}$ & $1,9^{a}$ & 0,04 \\
\hline
\end{tabular}

E.P.= Erro padrão. ${ }^{11}$ (muito magro) a 5 (obeso). ab Médias seguidas por letras diferentes na linha apresentaram diferenças significativas $(p<0,05)$. 
desempenho animal em relação ao capim Andropogon. Desta forma, no sistema modal da região, baseado no capim Andropogon, observou-se que o desempenho animal foi limitado não apenas pela reduzida quantidade de massa foliar, mas também, pelo baixo valor nutricional da forragem. O resultado de desempenho encontrado neste tratamento ficou bem próximo aos obtidos por Barbosa et al. (2003), de 35,0 g/animal/ dia, em pastagens de capim Aruana e de capim Tanzânia para animais sem suplementação concentrada.

O efeito do uso da suplementação concentrada, principalmente no período seco, é fator fundamental para ganhos médios diários superiores a $50 \mathrm{~g} / \mathrm{animal} / \mathrm{dia}$, comuns no período das águas. Trabalhos com ovinos Santa Inês, na fase de recria-terminação a pasto, no período seco, também apontaram para os efeitos positivos da utilização da suplementação concentrada em pastagem de $P$. maximum, com valores entre 82 a 119 $\mathrm{g} / \mathrm{animal} / \mathrm{dia}$ (Pompeu et al., 2005). Maiores

\section{BIBLIOGRAFIA}

Barbosa, C.M.P., Bueno, M.S. e Cunha, E.A. 2003. Consumo voluntário e ganho de peso de borregas das raças Santa Inês, Suffolk e île de France, em pastejo rotacionado sobre Panicum maximum Jacq. Cvs Aruana e Tanzânia. Bol. Indus. Anim., 60: 55-62.

Curi, C.C.S. 2004. Comportamento ingestivo e estimativa do consumo por ovinos pastejando Cynodon dactylon cv. Coastcross e Panicum maximum cv Aruana. Faculdade de Agronomia e Medicina Veterinária. Dissertação (Mestrado em Ciências Agrárias. Universidade de Brasília. Brasília. 37 pp. taxas de ganho de peso diário, particularmente na seca, possibilitam a redução no tempo de abate com potenciais ganhos econômicos em razão do aumento de ciclos de engorda no ano, da melhoria no fluxo de caixa e do retorno mais rápido do capital investido.

Em todos os tratamentos houve baixa deposição de gordura, característica da raça Santa Inês, aliado às condições experimentais com baixo valor nutritivo do pasto.

\section{CONCLUSÂO}

Ovinos suplementados com concentrado e mantidos em pastagens de Aruana e Tanzânia, durante o período da seca, apresentaram desempenho produtivo superior ao observado para os ovinos em capim Andropogon.

\section{AGRADECIMENTOS}

A Fazenda Nova Querência, em Luziânia (GO), Nutron, Finatec e CNPq.

Harlan, D.W., Holter, J.B. e Hayes, H.H. 1991. Detergent fiber traits to predict productive energy of forages fed free choice to nonlacting dairy cattle. J. Dairy Sci., 74: 1337-1353.

Pompeu, R.C.F.F., Cândido, M.J.D. e Neiva, J.N.M. 2005. Desempenho de ovinos em Panicum maximum cv. Tanzânia sob lotação rotativa com níveis crescentes de suplementação. Em: Reunião Anual da Sociedade Brasileira de Zootecnia, 42. 2005. Goiânia. Anais... Sociedade Brasileira de Zootecnia. Goiânia. 2005.

SAS. 1999. SAS System for Windows. Version 8.0. Cary: SAS Institute Inc. 2 CD-ROMs. 